\title{
33. Understanding resilience: Implications for the water sector
}

\author{
Heather M. Smith \\ Cranfield University, United Kingdom
}

Policy rhetoric around water resources and infrastructure increasingly emphasises the need to promote 'resilience' within water and wastewater systems. This trend is particularly evident in countries like the United Kingdom - take, for instance, the Water Services Regulation Authority's (Ofwat) recent report on the need for 'Resilient [water] supplies' (Ofwat 2010). The UK Government also recently published the Water for Life White Paper (Department for Environment, Food and Rural Affairs (DEFRA) 2011), which outlines its strategy for reforming the water sector and stresses the need to develop 'secure, sustainable and resilient water resources'.

It is worth questioning, however, whether 'resilience' has simply joined a long list of intuitively appealing yet stubbornly intangible concepts (e.g., 'sustainability'). It's certainly no easy matter to define resilience, or specify what a resilient system might look like.

Some are certainly trying to pin the concept down more firmly - for instance the European Union (EU)-funded Transitions to the Urban Water Services of Tomorrow (TRUST) project is aiming, in part, to understand and promote resilience within urban water cycle systems. The work builds on previous efforts to define the idea, such as the US National Infrastructure Advisory Council's report on Critical Infrastructure Resilience (NIAC 2009), which states:

Infrastructure resilience is the ability to reduce the magnitude and/or duration of disruptive events. The effectiveness of a resilient infrastructure or enterprise depends upon its ability to anticipate, absorb, adapt to, and/or rapidly recover from a potentially disruptive event.

In light of this definition, infrastructure resilience is about delivering services, regardless of disruptive events that may occur — the ability to 'take a licking and keep on ticking' (to quote the old Timex slogan). This understanding of resilience seems to be a relatively common one in the water sector, and reports from the United Kingdom echo it.

Water and wastewater systems, however, are more than the sum of their engineered parts. They can be described as socio-technical or socio-ecological systems, as they involve complex interactions between human, technological 
and environmental components. And, among researchers who study the behaviour of such big systems, the idea of resilience has broad implications. Its origins are often traced to early developments in the field of ecology.

In the 1970s, ecological theory was dominated by the idea that ecosystems have a single, relatively fixed point of equilibrium - one 'steady state'. Resilience was, therefore, seen as an ecosystem's ability to recover from disturbance and return to equilibrium. A common analogy is a rubber band - a resilient system could be subjected to stress and strain, but ultimately had the ability to return to its original state. The shorter the 'return time', the more resilient the system. This was referred to as 'engineering resilience' (Folke et al. 2010).

There were, however, those who challenged the idea that ecosystems have one single steady state. Holling (1973) proposed instead that ecosystems have multiple 'domains of stability', and that they could (and did) shift between these alternate steady states. Holling therefore viewed ecosystems as fundamentally dynamic - 'disturbance' is the rule rather than the exception and, in response to disturbance, systems are continually changing and developing, not just returning to the same point of equilibrium.

This also creates an alternative view of resilience, which can be seen as a system's ability to absorb disturbances and reorganise itself into a better configuration, while still retaining its fundamental characteristics (Walker et al. 2004). In this view, resilient systems are less like rubber bands and more like plasticine when subjected to stress they can adopt and retain a suitable new shape, rather than return to their original state.

It's no wonder, then, that the concept of resilience has, for some, become nearly synonymous with ideas of adaptability and adaptive management - ensuring that systems have the ability to adjust in order to suit changing circumstances. These ideas are increasingly applied to social systems, particularly those focused on environmental/resource management. They are also becoming more powerful in light of climate change, as we increasingly have to ask ourselves how to manage for the unexpected.

For the water sector, these ideas imply moving beyond 'engineering resilience', and the traditional 'predict and withstand' approach for extreme conditions, towards a more dynamic and flexible system. There is, however, inevitable tension here - namely, can these ideas fit within a system that relies heavily on inflexible assets like pipes and treatment plants?

There are ways of making the built infrastructure more flexible and adaptable. On the water-supply side, for instance, two strategies are often suggested diversification and connectivity. Diversification implies incorporating a broad range of source options within a water system, so that if one source is disrupted, 
others can help to compensate (Staub and Moreau-Le-Golvan 2011). Similarly, the United Kingdom's recent water white paper argues that improving connectivity between water supplies in different parts of the country (e.g., by encouraging water companies to share/trade water) will lead to a similar result (DEFRA 2011).

There are also ways of introducing flexibility within patterns of water demand. For instance, the scheme devised for the California San Francisco Bay/San Joaquin Delta water management program (CALFED) allowed different groups of users to 'trade' water allocations, so that patterns of use could be swiftly adjusted as water availability changed. This helped to overcome the frequent conflicts and stalemates that arose over allocations, and helped ensure that water was used where it was needed most (Booher and Innes 2010).

There is, however, significant uncertainty around such approaches. For instance, how much flexibility is needed or appropriate? Additionally, some argue that fostering resilience means supporting innovation and experimentation - in other words, allowing room for developing and trialling new technologies and new management approaches, learning from the outcomes and, perhaps most importantly, acting on those lessons learned (Olsson and Galaz 2009). Similarly, some argue that it means favouring reversible decisions over irreversible ones (Staub and Moreau-Le-Golvan 2011). But when it comes to planning future water infrastructure, especially large-scale assets, such ideas can be something of a luxury.

Planning processes may favour options with known benefits and consequences, particularly when spending must be justified to consumers and/or public bodies. For something as fundamental as water, it can be difficult to foster an appetite for creativity and experimentation. Furthermore, given the lengthy timeframes over which large-scale projects are decided and implemented, and the level of investment required, it is hardly feasible to ensure that all such decisions are reversible.

These challenges are certainly not unique to the water sector, and there are no easy answers for them. It is nonetheless important that they are considered and debated if resilience is to become a true operational concept, and not simply an intuitively appealing buzzword.

Dr Heather Smith is an Academic Fellow in Water Governance at Cranfield University. Her research examines the intersections between science, policy, social drivers and management decisions around water services, with a particular emphasis on the adoption of innovative technologies and practices in the water sector. Her PhD from the University of Aberdeen focused on the implementation of the EU Water Framework Directive. 
Global Water: Issues and Insights

\section{References}

Booher, D.E. and Innes, J.E., 2010. 'Governance for resilience: CALFED as a complex adaptive network for resource management', Ecology and Society 15(3):35.

Department for Environment, Food and Rural Affairs (DEFRA), 2011. Water for Life, London.

Folke, C., Carpenter, S.R., Walker, B., Scheffer, M., Chapin, T. and Rockström, J., 2010. 'Resilience thinking: integrating resilience, adaptability and transformability', Ecology and Society 15(4):20.

Holling, C.S., 1973. 'Resilience and stability of ecological systems', Annual Review of Ecology and Systematics 4(1):1-23.

National Infrastructure Advisory Committee (NIAC), 2009. Critical Infrastructure Resilience: Final report and recommendations, Washington D.C.

Olsson, P. and Galaz, V., 2009. 'Transitions to adaptive approaches to water management and governance in Sweden', in D. Huitema and S. Meijerink (eds) Water Policy Entrepreneurs: A research companion to water transitions around the globe, Edward Elgar Publishing, Cheltenham.

Staub, M. and Moreau-Le-Golvan, Y., 2011. 'Catalogue of European adaptive initiatives of the water sector to face climate change impacts', PREPARED Report.

Walker, B., Holling, C.S., Carpenter, S.R. and Kinzig, A., 2004. 'Resilience, adaptability and transformability in social-ecological systems', Ecology and Society $9(2): 5$.

Water Services Regulation Authority (Ofwat), 2010. Resilient supplies: How do we ensure secure water and sewerage services?, London. 
This text taken from Global Water: Issues and Insights by R. Quentin Grafton, Paul Wyrwoll, Chris White and David Allendes, published May 2014 by ANU Press, The Australian National University, Canberra, Australia. 